\title{
A INTEGRAÇÃO ENTRE A EDUCAÇÃO AMBIENTAL E A COMUNIDADE LOCAL: SEMENTE PARA UM FUTURO SUSTENTÁVEL
}

\author{
Cláudio José Donato ${ }^{1,2}$, Irene Caires da Silva ${ }^{1}$, José Luís de Lima Astolphi ${ }^{1}$, Joselene Lopes Alvim ${ }^{1}$, \\ Maira Rodrigues Uliana ${ }^{1}$, Taís Muller ${ }^{3}$. \\ ${ }^{1}$ Universidade do Oeste Paulista - UNOESTE, ${ }^{2}$ Mestrado em Meio Ambiente, Presidente Prudente, SP. ${ }^{3}$ Universidade \\ Estadual de Maringá - Campus de Umuarama, Curso de Engenharia Ambiental, Umuarama, PR. E-mail: \\ claudio.donato@hotmail.com.
}

\section{RESUMO}

As atividades de Educação Ambiental são imprescindíveis na formação e preparação de cidadãos para a adoção de medidas corretivas e/ou transformadoras dos problemas ambientais atuais. Grande parte desses problemas é ocasionada devido à grande exploração e degradação dos recursos naturais consequente do modelo atual de desenvolvimento. Para minimizar esses impactos negativos ao meio ambiente é importante que sejam realizadas atividades de Educação Ambiental tanto com crianças, como para adolescentes, jovens, e/ou idosos. Diante deste cenário, esse artigo busca mostrar a importância de atividades voltadas para o desenvolvimento sustentável destinada à educação das pessoas, a fim de minimizar as formas de agressão ao meio ambiente com abordagens sobre o próprio ambiente. Com a execução desse artigo espera-se que as pessoas envolvidas sejam capazes de perceber e propor medidas que minimizem os impactos ambientais negativos causados pela influência humana no ambiente natural.

Palavras-Chave: Sustentabilidade. Meio Ambiente. Educação Ambiental. Cidadania.

THE INTEGRATION OF ENVIRONMENTAL EDUCATION AND THE LOCAL COMMUNITY: SEEDS FOR A SUSTAINABLE FUTURE

\begin{abstract}
Environmental education activities are essential in the formation and preparation of citizens for adoption of corrective measures and/or processing of current environmental problems. A large part of these problems are caused due to the exploitation and degradation of natural resources resulting from the current model of development. To minimize these negative impacts to the environment it is important that environmental education activities with children, as for teenagers, young, and/or elderly. Given this scenario, this article seeks to show the importance of activities aimed at the sustainable development for the education of people, in order to minimize the forms of aggression to the environment with approaches on the environment itself. With the implementation of this article it is expected that the people involved are able to understand and propose measures that minimize negative environmental impacts caused by human influence on the natural environment.
\end{abstract}

Keywords: Sustainability. Environment. Environmental Education. Citizenship. 


\section{INTRODUÇÃO}

O ser humano tem desenvolvido ao longo dos tempos sua trajetória pautada na busca por comodidade e praticidade para a vida cotidiana. Porém, esse fato tem sido gerador de desigualdades sociais, pois, ao passo que um indivíduo busca seu conforto e de sua família, acaba por esquecer a coletividade, o bem comum. $E$ isso é fortemente alimentado pelo sistema capitalista, que visa o lucro imediato e promove o individualismo. Daí as consequências graves geradas ao redor do mundo: os desequilíbrios socioambientais.

A questão ambiental tem sido cada vez mais discutida e, aos poucos, tem aumentado o número de pessoas que dedicam parte de seu tempo para contribuir, de uma forma ou de outra, para a solução dos problemas gerados pelo desequilíbrio entre os ecossistemas, especialmente onde vive o ser humano. Durante muito tempo o homem buscou formas práticas de sobrevivência, sem se preocupar com os resultados de sua interação com a natureza.

Sendo assim, busca-se neste artigo mostrar a importância de atividades voltadas para o desenvolvimento sustentável destinada à educação das pessoas, com o intuito de minimizar as formas de agressão ao meio ambiente com abordagens sobre o próprio ambiente.

Deste modo, pretende-se a partir deste trabalho, mostrar que com o envolvimento de todos é possível construir uma nova realidade, levando em consideração o cuidado e responsabilidade com o planeta em que vivemos.

\section{METODOLOGIA}

Para o alcance do objetivo traçado, o estudo foi desenvolvido a partir da pesquisa bibliográfica, que segundo Gil (2010, p.71) este tipo de pesquisa "[...] é desenvolvida a partir de material já elaborado, constituído principalmente de livros e artigos científicos". Sendo assim, as fontes de informações e conhecimentos dessa pesquisa constituem-se em livros, artigos, publicações e sites na internet, relacionado ao tema do trabalho.

\section{RESULTADOS}

As Constituições que precederam o Texto Constitucional de 1988 não tinham nenhum cunho ou preocupação com a proteção ambiental, nem em questões de interesse interno, tampouco em escala global.

Assim, a Constituição Federal de 1988 foi primeira constituição brasileira em que a expressão "meio ambiente" é mencionada (MACHADO, 2013).

Confirmando o exposto pelo autor acima, Silva (2009), menciona que ela é uma Constituição eminentemente ambientalista.

Desta forma, em alguns aspectos a Constituição de 1988 pode ser designada "verde", devido à ênfase dada à proteção do meio ambiente, valendo-se de uma consciência que se faz necessária para aprender a conviver harmoniosamente com a natureza.

Visto isto, a Constituição de 1988 consolidou o processo legal e institucional, criando um capitulo exclusivo para tratar de assuntos ambientais, enfatizando a necessidade de defender e proteger o meio ambiente, bem como estabelecer seus respectivos mecanismos para ajudar no processo, para que se concretize sua preservação.

Dentro desse raciocínio, faz-se interessante saber que a proteção ao meio ambiente, tem um valor fundamental, revestido de um caráter comunitário, por ser um direito difuso, a ser protegido para as presentes e futuras gerações, deflagrado pelo Principio da Solidariedade Intergeracional", que visa de forma solidária, garantir o meio ambiente saudável para todos os seres humanos.

Deste modo, Fiorillo (2006) estabelece válida a relação entre a necessidade de preservação ambiental e a sua percepção humanística, esta decorrente da deflagração de solidariedade que se expandiu pelo Planeta, em especial pelos movimentos e convenções internacionalmente realizados, 
bem como a percepção de que tal direito é inerente à natureza humana; no entanto, ambos não são suficientes para sua inserção como direito fundamental.

Assim, a Educação Ambiental é imprescindível na evolução educacional da sociedade, que se ajusta a nova realidade mundial, realidade esta que pede comprometimento com o crescimento sustentável, com intensa participação na preservação dos recursos naturais.

As atividades de Educação Ambiental desempenham fundamental importância na formação e preparação de cidadãos para a reflexão crítica e para uma ação social corretiva ou transformadora dos problemas ambientais atuais (PHILIPPI JÚNIOR; PELICIONI, 2005). Parte desses problemas é devido ao modelo de desenvolvimento atual que exerce forte pressão sobre os recursos naturais, visto que, normalmente, há uma exploração da água, das matérias-primas, combustíveis e solos aumentando o nível de degradação, afetando a qualidade de vida em várias escalas, de acordo com o potencial causador do impacto.

Em função desse modelo de desenvolvimento, o ambiente natural está sofrendo várias alterações adversas como à alteração climática, a poluição do solo, da água e do ar atmosférico, o assoreamento dos rios e lagos, a destruição de habitats, a escassez de água potável e a consequente perda da biodiversidade e a exclusão social (DIAS, 2004).

Para minimizar as formas de agressão ao meio ambiente é importante que a educação de crianças, adolescentes e jovens tenha uma abordagem abrangente incluindo o ambiente em que se encontra. A importância dessa abordagem é devida ao potencial de estimular as pessoas a questionarem os seus valores, os modelos vigentes e de propor relacionamentos mais harmônicos entre os seres vivos do planeta (FUNDAÇÃO ESTADUAL DO MEIO AMBIENTE, 2003).

\section{DISCUSSÃO}

Uma comunidade sustentável pode ser definida como aquela "capaz de satisfazer as suas necessidades e aspirações sem diminuir as chances das gerações futuras" (CAPRA et al., 2006, p.13).

A base de um desenvolvimento sustentável não é a criação de comunidades humanas sustentáveis a partir do zero. A sustentabilidade norteia-se do princípio de se aprender com as sociedades que se sustentaram durante muitos e muitos séculos. Diante essa visão, preconiza-se a capacidade para se moldar sociedades humanas de acordo com os ecossistemas naturais, que são comunidades sustentáveis de plantas, animais e microorganismos. A possibilidade está focada nas características provenientes da biosfera em sua capacidade de sustentar a vida. Para a proeza desse evento, uma comunidade sustentável deve ser planejada, de modo que os estilos de vida, tecnologias e instituições sociais respeitem, apoiem e cooperem para a realização desse evento.

O processo de construção do desenvolvimento sustentável deve priorizar estudos e compreensão das questões sociais, econômicas, ambientais, tecnológicas e políticas, presentes na sociedade humana e no ambiente na qual se insere. Nesse contexto, é fundamental que a comunidade se inteire da real situação social, econômica e ambiental, participando, por exemplo, de processos de licenciamento ambiental para implantação de empreendimentos, cujas atividades apresentam riscos inerentes ao meio ambiente à sadia qualidade de vida (PHILIPPI JÚNIOR; PELICIONI, 2005).

A educação ambiental por uma vida sustentável estimula o entendimento intelectual da ecologia podendo criar vínculos emocionais com a natureza. Nesse contexto, ela dispõe da possibilidade de desenvolver na educação infantil de crianças, juniores, adolescentes, jovens e adultos a capacidade de uma paixão pela aplicação dos seus conhecimentos ecológicos à reformulação das tecnologias formais e das instituições sociais, preconizando preencher o buraco existente entre a prática humana e os sistemas da natureza ecologicamente sustentáveis (CAPRA et al., 2006). 
A Educação Ambiental é participativa e não pode desvincular as condições de seu entorno, que exigem dela respostas inovadoras no propósito de formar cidadão crítico, reflexivo e participativo, apto para a tomada de decisões, que sejam condizentes com a consolidação de democracias verdadeiras e sem exclusão da maioria de seus membros (MEDINA; SANTOS, 2003).

Além disso, a Educação Ambiental é o fator determinante do saber sócio-ambiental, onde se aprendem na prática, as teorias. Esse saber nasce do fruto educativo materializado nos valores éticos e nas regras políticas do convívio social e de mercado que implica a questão distributiva entre benefícios e prejuízos da apropriação e do uso da natureza. Um saber para fundamentar a compreensão da essência de um trabalho em rede e buscar o entendimento da comunidade para formulação, ação e transformação, priorizando - os a sintonizar e harmonizar o sentimento de pertencer ao lugar onde vive e atuar através de uma pedagogia intitulada educação para uma vida sustentável (CAPRA et al., 2006).

Assim, a construção de uma sociedade com dimensões culturais ecológicas deve ser um processo educativo voltado para a percepção quanto aos problemas relativos de valores. Para que isso aconteça é necessário que ocorra mudança nos valores por meio de experiências e das práticas e reflexões em milhares e milhares de pessoas. A concepção de valor para as pessoas adultas é algo concreto, difícil de mudar, ao passo que para as crianças, o sentimento de espanto ou reverência e afinidade com a natureza nascem com certos valores intactos. Esses valores devidamente nutridos para a promoção da alfabetização ambiental pode ser uma ferramenta ecológica transformadora e corretiva do sistema conduzindo a uma sociedade mais sustentável.

A Educação Ambiental deve, consequentemente,

ser direcionado para a cidadania ativa considerando seu sentido de pertencimento e corresponsabilidade que por meio da ação coletiva e organizada, busca a compreensão e superação das causas estruturais e conjunturais dos problemas ambientais. Trata-se de construir uma cultura ecológica que compreenda a natureza e sociedade como dimensões intrinsecamente relacionadas e que não podem mais ser pensadas - seja nas decisões governamentais, seja nas ações da sociedade civil - de forma separada, independente ou autônoma (CARVALHO, 2012, p.425).

Neste contexto, a realização de atividades de Educação Ambiental é de extrema importância para que crianças e, consequentemente, as pessoas que estão relacionadas com as mesmas, tenham no seu processo de socialização, comportamentos ambientais que contribuam para a formação de cidadãos responsáveis.

Pensar em meio ambiente significa incluir, correlacionar e interagir o mundo globalizado, o "sistema natural", composto do meio físico e biológico e o "sistema antrópico". Despertar a sensibilização e conscientização ambiental em crianças pode contribuir com uma relação harmônica entre o "homem" e o "meio ambiente" e, portanto, minimizar impactos negativos que sejam contrários aos princípios de uma organização social.

\section{CONCLUSÃO}

No decorrer deste trabalho, pode-se verificar que, os problemas relacionados com o meio ambiente e o desenvolvimento sustentável não interessam apenas aos governos e aos cientistas. Nem são só eles que têm que solucioná-los. Nós também podemos e devemos contribuir com pequenos gestos, como, por exemplo, usando artigos reciclados ou esforçando-nos para usar com moderação recursos escassos e não renováveis. As empresas também terão que rever seus processos produtivos, levando em conta os critérios da sustentabilidade. Além do respeito pela natureza e o meio ambiente, o desenvolvimento sustentável tem também uma dimensão social. 0 mundo tampouco será sustentável se persistirem as vastas e profundas desigualdades econômicas 
e sociais que ainda afligem muitos países, incluindo o Brasil.

O tema ambiental e social traz então questões desafiantes como a organização de projetos que atendam aos mais diversos aspectos e entre estes, a Educação Ambiental.

Assim, faz-se necessário um conhecimento amplo e não fragmentado de concepções éticoambientais e sociocultural de práticas educativas que propiciem uma compreensão real e crítica da situação atual numa visão global, nacional, regional e local, para com isso despertar atitudes que visem dinâmica e sensibilização, cuja participação envolva todos: escolas, professores, alunos, família e comunidade.

Após a realização deste trabalho pode-se ainda concluir que é possível articular e planejar ações entre a comunidade escolar e local, relacionando e interagindo o conhecimento ao saber popular tornando-o contextualizado e inserido suas reais necessidades dos indivíduos em prol da melhoria da qualidade de vida e dignidade humana.

O crescimento global é o grande desafio de construir um desenvolvimento sustentável, que valorize os recursos naturais e humanos, visando à melhoria da qualidade e a edificação de uma sociedade sustentável capaz de superar os problemas atuais e utilizar as potencialidades existentes no país.

\section{REFERÊNCIAS}

BRASIL. Constituição (1988). Constituição da República Federativa do Brasil. Brasília: Senado, 1988.

CAPRA, Fritjof et al. Alfabetização Ecológica: a educação das crianças para um mundo sustentável. São Paulo: Cultrix, 2006.

CARVALHO, Izabel Cristina de Moura. Educação Ambiental: a formação do sujeito ecológico. 6. ed. São Paulo: Cortez, 2012.

DIAS, Genebaldo Freire. Educação Ambiental: princípios e práticas. 9. ed. São Paulo: Gaia, 2004.

FIORILLO, Celso Antonio Pacheco. Curso de direito ambiental brasileiro. 7. ed., rev., atual. e ampl. São Paulo: Saraiva, 2006.

FUNDAÇÃO ESTADUAL DO MEIO AMBIENTE (MG). Iniciação ao Desenvolvimento Sustentável. Belo Horizonte: FEAM, 2003.

GIL, Antônio Carlos. Como elaborar projetos de pesquisa. 5. ed. São Paulo: Atlas, 2010.

MACHADO, Paulo Affonso Leme. Direito Ambiental Brasileiro. 21 . ed., rev., atual. e ampl., de acordo com as Leis $12.651 / 2012$ e 12.727/2012 e com o Decreto 7.830/2012. São Paulo: Malheiros, 2013.

MEDINA, Naná Mininni; SANTOS, Elizabeth da Conceição. Educação ambiental: uma metodologia participativa de formação. 3. ed. Petrópolis: Vozes, 2003.

PHILIPPI JÚNIOR, Arlindo; PELICIONI, Maria Cecília Focesi (ed.). Educação ambiental e sustentabilidade. Barueri: Manole, 2005.

SARAIVA, Vanda Maria; NASCIMENTO, Kelly Regina Pereira do; COSTA, Renata Kelly Matos da. A prática pedagógicas do ensino de educação ambiental nas escolas públicas de João Câmara - RN. 
Disponível em: <http://www2.ifrn.edu.br/ojs/index.php/HOLOS/article/viewFile/187/157>. Acesso em: 02 ago. 2017.

SILVA, José Afonso da. Direito Ambiental Constitucional. 7. ed. São Paulo: Malheiros, 2009. 